Original article

\title{
How respectfully women are treated during difficult phase like childbirth? A primary survey of differently-managed health facilities in Odisha, India
}

\author{
Jitendra Gouda ${ }^{\mathrm{a}, *}$, Chander Shekhar ${ }^{\mathrm{b}}$ \\ ${ }^{a}$ Office of the Registrar General of India, Ministry of Home Affairs, India \\ ${ }^{\mathrm{b}}$ Department of Fertility Studies, International Institute for Population Sciences, Govandi Station Road, Deonar, Mumbai, 400088, India
}

\section{A R T I C L E I N F O}

\section{Keywords:}

Respectful maternity care

Childbirth

Health facility and odisha

\begin{abstract}
A B S T R A C T
Objective: The study was explorative in nature, implemented at hospital level to investigate how respectfully women are treated while accessing delivery care in the health facilities.

Methods: A total of 115 differently-managed i.e. public, private and public-private partnerships (PPP) health facilities in Ganjam and Kandhamal districts of Odisha were selected to undertake this study. Three women each having given childbirth in the last six months preceding the survey in the sampled 115 health facilities were selected randomly to participate in the study.

Results: The result presented a distinct picture wherein provision of respectful maternity care is not uniform for all the respondents included in the study. Management of the health facility remained as the major transpiring factor to providing respectful maternity care. Public health facility (ATT: 5.503) - which happened to be the largest service provider in the study population, affects respectful maternity care adversely. Contrary to this, women having accessed delivery care from the PPP facilities received more respectful maternity care. The private facilities whose number is mushrooming alarmingly at the present time also fails to provide the needed respectful maternity care to women during their difficult phase like childbirth.

Conclusion: Women's memory of birth experience including any disrespectful and abusive care stays with her lifetime and affects her physical and emotional health. It may also discourage her to have institutional delivery by which, opportunities may be lost to diagnose morbidities early that are associated with pregnancy and childbirth.
\end{abstract}

\section{Introduction}

Reproduction is considered as a major aspect of female's role and continued to be basic to the genesis of the ideology about women. And, women regard motherhood as a positive and fulfilling experience. ${ }^{1}$ In India, motherhood is celebrated with so much pride and admiration. It is often regulated with inevitable socio-cultural values and viewed as necessary to continue the family lineage. ${ }^{2}$ Women receive special attention and care since her conception to till childbirth from the family members. The family give every effort to make her journey to becoming a mother pleasant. ${ }^{3,4}$ Apart from the family care, essential effort is also put in place to provide the best of medical care during her gestation and at the time of delivery. The recently concluded National Family Health Survey (NFHS-4, 2015-16) reckons such emerging development in India. As the survey suggest, the percentage of women who had at least 4 antenatal care visits increased to $51 \%$ in $2015-16$ from $37 \%$ in 2005-06. Births assisted by skilled birth personnel increased from less than half (47\%) to $81 \%$ during $2005-2016$. Women with institutional births also doubled (in 2005-06, it was $38.7 \%$ that increased to $78.9 \%$ in 2015-16) during this period. ${ }^{5}$ Although, such development at the national level is significant to advance India's position on public health globally, there are still large number of women who experience suffering, ill health and even death in different parts of India. ${ }^{6,7}$ Most of the illness or deaths are pregnancy-induced, occurs during pregnancy, at childbirth or within 42 days after the birth. ${ }^{8}$ The situation is even worse among the disadvantaged socioeconomic group or in the difficult geographical regions. ${ }^{9,10}$ A wide range of factors found to have transpired for such unequal distribution of maternal morbidity and mortality in the country. In a nutshell, poverty, illiteracy mainly among women, lack of proper nutrients in the diet, unhygienic sanitary conditions and absence of medical care remained as the foremost correlates of high maternal morbidity and mortality. ${ }^{5,11,12}$

Beside this, an important but little understood component of high maternal morbidity and mortality is disrespectful and abusive

\footnotetext{
* Corresponding author.

E-mail addresses: jitushome@gmail.com (J. Gouda), shekhariips@rediffmail.com (C. Shekhar).
} 
behaviour by the health workers and other staffs in the health facilities. ${ }^{13}$ Large number of studies primarily from African countries found that, women with certain individual characteristics are often physically abused, neglected and abandoned, discriminated or asked to pay extra payment while undergoing difficult phase like during childbirth. In certain cases, the abusive care or the negligence by the health facility staffs is fatal in nature. ${ }^{14}$ This symbolizes the existence of biasness in the healthcare system. In India, with considerable gaps in services, emphasis has always been placed on increasing physical access, but efforts to ensure quality of care and recording women's needs and perception during the maternal healthcare have not been sufficient. ${ }^{15-17}$ Studies have also found that, women from better socioeconomic backgrounds receive all the necessary information related to family planning more than their counterpart women with poor socioeconomic characteristics. Addition to this, post-delivery sterilization of poor women without their knowledge is not uncommon in India which is often justified to meet the family planning targets and to control the population. ${ }^{18,19}$ While, these studies can address certain aspects of quality of care, it predominantly restricts to any single dimension or largely of family planning service. However, there are many such discrepancy exist in healthcare delivery system that are sensitive in nature, but do not find the needed care and attention.

Respectful and non-abusive birth care for all women has achieved agreed importance among maternal health and human rights stakeholders in India recently, ${ }^{20}$ yet, there has been a relative lack of formal research around this topic. With this backdrop, the present study attempted to shed light on, how respectfully women are treated during childbirth - which happened to be the most vulnerable phase of women's life. The study is expected to produce evidence of any non-dignified and abusive care in facility-based childbirth and to highlight the aspects of care that women value most during childbirth. This is essential to generate support for the existing health policies and programs that advocate to increasing institutional births with a long term aim to bring appreciable reduction in the maternal mortality in India.

\section{Data and methods}

The study was explorative in nature conducted during January to March 2016 in Odisha - a high-focused state for its poor maternal health indicators in India. ${ }^{8,21}$ Respondents were selected cross-sectionally from three differently-managed i.e. public, private and publicprivate partnership (PPP) health facilities. A total of 115 (public 60; private 40; PPP 15) health facilities where delivery care is provided were identified in Ganjam and Kandhamal districts of Odisha to undertake this study. From the total 30 districts in the state, Ganjam and Kandhamal districts situated in South and Western part of Odisha were selected to conduct this study. As per the Human Development Index report, Ganjam (0.551) and Kandhamal (0.389) stands at 20th and 29th position in the state. ${ }^{22}$ These two districts differs largely on socioeconomic and demographic characteristics. The topographies of the selected districts also varies significantly. Ganjam is situated in coastal region whereas, Kandhamal is a tribal dominated district and geographically mountainous. Additionally, for the advantage, the selected districts have more than one quarter $(28 \%)$ of total PPP health institutions in the state, from where respondents were selected for comparative purpose in the present study.

A total of 345 (three women each from 115 health facilities) women having received delivery care in the last six months preceding the survey in the included health facilities were selected randomly for the interview. However, only 322 respondents could be interviewed. Due to non-cooperation, information from rest of the women could not be ascertained. The standard toolkit developed by USAID for its $\mathrm{MCH}$ program was employed to gather information related to the experience of women during childbirth. ${ }^{23}$ In addition, structured interview schedule was used to collect data about the individual and household characteristics of the respondents. Focused Group Discussions (FGDs) and In-Depth interviews (IDs) were also used to collect qualitative information from health personnel and respondents to supplement any quantitative inferences. Tools were piloted to check its reliability and necessary changes in the tools were undertaken before its use in the final data collection process. Interviews of respondent were conducted at their respective home to control the influence of any extraneous variable like the presence of facility staffs which might have affected the quality of information ascertained from the respondents.

\section{Statistical interpretation}

Inferential statistics and bivariate analysis were carried out to examine the level and pattern of respectful maternity care during childbirth. Using principal component analysis (PCA), a composite respectful maternity care index was created to examine its variation across selected covariates. The alpha ( $\alpha=0.7137)$ value suggested that, the included components are good enough to define much of the variability in the respectful maternity care index at childbirth. Chi-square at $95 \%$ level of significance was used to check the statistical significance of any association studied in the bivariate analysis. Further, propensity score matching (PSM) - a robust and an innovative statistical technique was used to analyse the net effect of each health facility on respectful maternity care - outcome of the interest.

\subsection{Calculation of propensity score}

It is the probability that a woman will use a specific health facility for maternal healthcare services, given her various background characteristics.

$p(\mathrm{X})=\operatorname{Pr}(D=1 \mid \mathrm{X})$

Where, $D=\{0,1\}$ is the indicator of exposure to use any specific health facility for the maternal healthcare services and $\mathrm{X}$ is the vector of pre health facility visits characteristics.

\subsection{Calculation of treatment effect}

$\mathrm{Y}^{1}$ is the outcome for the women who visited private or PPP facilities whereas $\mathrm{Y}^{0}$ is the outcome for the women who sought maternal healthcare from public health facilities.

$y=\begin{aligned} & y 1 \text { if } \mathrm{D}=1 \\ & y 0 \text { if } \mathrm{D}=0\end{aligned}$

the impact of visits to any specific health facility for a woman i, noted $\delta \mathrm{i}$, is defined as the difference between the potential outcome in the presence of (for example: visiting to non-public facilities) and the potential outcome in the absence of visits (for example: visiting public facilities).

$\delta_{\mathrm{i}}=\mathrm{y}^{1}-\mathrm{y}^{0}$

The treatment effect is obtained by averaging the impact across all the women in the population. This parameter is known as Average Treatment Effect (ATE).

$\mathrm{ATE}=E(\delta)=E\left(\mathrm{y}^{1}-\mathrm{y}^{0}\right)$

Where $\mathrm{E}$ (.) represents the average.

\subsection{Counterfactual situation}

For an ideal comparison, the controlled group either needs to be assigned treatment or the treatment from the treated group needs to be taken away which is not possible in observational or cross sectional studies. For this reason, the only way-out that remain was to find some close matches for those treated observations and then use their outcomes to compare with the outcomes of the controlled observation that are similar to each other. In other words, counterfactual is the potential 
outcome, or the state of affairs that would have happened in the absence of the cause. This model guides the estimation of visits to nonpublic facilities.

With the help of this model, Average Treatment Effect on the Treated (ATT) has been calculated. This measures the impact of the treatment on treated women.

$\mathrm{ATT}=\mathrm{E}(\mathrm{Y} 1 \mid \mathrm{D}=1)-\mathrm{E}(\mathrm{YO} \mid \mathrm{D}=1)$

Where $\mathrm{E}(\mathrm{Y} 1 \mid \mathrm{D}=1)$ is the average outcome of the women who have visited a private or PPP health centre. Whereas, E (Y0 $\mid \mathrm{D}=1)$ is the counterfactual, it shows average outcome that the treated individuals would have obtained in absence of visits to private or PPP facilities, which is unobserved.

Data was entered using the Statistical Package for Social Science (SPSS). The entered data file then transformed into STATA 12 version for the statistical analysis purpose.

\section{Results}

Nearly, three-fourth (74\%) of the respondents had paid informal fees to have delivery in the health facility. Only half of the respondents reported that, her companion was allowed to stay with her wherever it was necessary and $52 \%$ of respondents opined that, clean cloth or Macintosh sheet was used during her childbirth. More than one-third each of respondents were denied food or fluid in labour unless it was medically necessary and harassed by doctors while assisting her during childbirth respectively (Fig. 1).
Respondents having used private and PPP facilities received more respectful maternity care than their counterpart respondents who used public facilities. This pattern was observed across the selected respectful maternity care indicators. Nearly, half of respondents in public facilities were denied to have food or fluid in labour unless it was medically necessitated. The corresponding figures in private and PPP facilities were $25 \%$ and $13 \%$ respectively ( $p<0.001$ ) (Table 1 ).

In an in-depth interview, Anita Bhoi (name changed) a semi-literate respondent having delivered (DOB: Dec 4, 2015) her baby in the district (Kandhamal) government hospital complained that, "Some health personnel made video and took photographs during my delivery. All this was done without my consent. When my husband complained about such act, he was asked to cooperate to receive the medical care."

A young mother Topai-Majhi(name changed) (delivered at age 18 years) shared her experience that, "I was physically restrained during labour pain. I was actually beaten by the staff nurse and was pinched harshly. $M y I V$ vain flow set was also removed without much care. (Women in a FGD, Kulada).

The composite index of respectful maternity care during childbirth suggest that, respondents having delivered baby in private $(61 \%)$ and PPP (50\%) facilities received high level of respectful care more than their counterpart respondents who received delivery care in public facilities (14\%). More than half (56\%) of respondents in public facilities received low level of respectful maternity care in the study. The association was found to be statistically significant at $\mathrm{p}<0.001$ (Fig. 2).

Respondents in urban (59\%), other than SCs, STs and OBC social

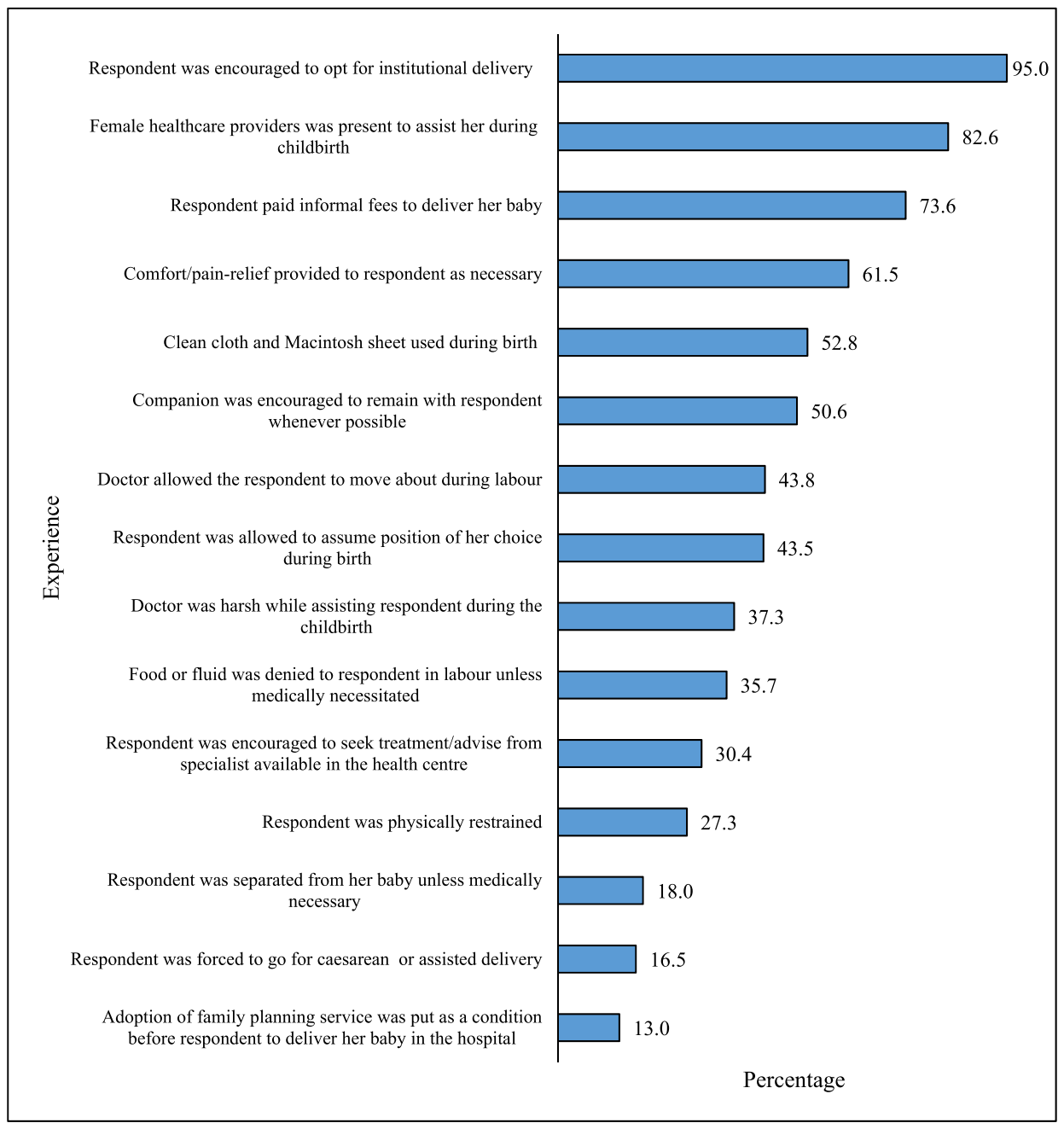

Fig. 1. Experience of respondents while having childbirth in Odisha. 
Table 1

Experience of respondents while having childbirth by health facility.

\begin{tabular}{|c|c|c|c|c|c|c|}
\hline \multirow[t]{2}{*}{ Indicators of respectful maternity care during Delivery care } & \multirow[t]{2}{*}{ Total } & \multicolumn{3}{|c|}{ Health facility } & \multirow{2}{*}{\multicolumn{2}{|c|}{ P Value }} \\
\hline & & Public & Private & PPP & & \\
\hline Woman was encouraged to opt for institutional delivery & 95.0 & 95.0 & 93.1 & 100.0 & & \\
\hline Woman was encouraged to seek treatment/advise from specialist available in the health centre & 30.4 & 19.4 & 43.1 & 47.5 & $\mathrm{p}$ & $<0.001$ \\
\hline Companion was encouraged to remain with woman whenever possible & 50.6 & 35.6 & 68.6 & 72.5 & $\mathrm{p}$ & $<0.001$ \\
\hline Food or fluid was denied to woman in labour unless medically necessitated & 35.7 & 47.2 & 24.5 & 12.5 & $\mathrm{p}$ & $<0.001$ \\
\hline Doctor allowed the woman to move about during labour & 43.8 & 25.0 & 73.5 & 52.5 & $\mathrm{p}$ & $<0.001$ \\
\hline Comfort/pain-relief provided to woman as necessary & 61.5 & 52.2 & 75.5 & 67.5 & $\mathrm{p}$ & $<0.001$ \\
\hline Adoption of family planning service was put as a condition to deliver her baby in the hospital & 13.0 & 11.7 & 19.6 & 2.5 & $\mathrm{p}$ & $<0.05$ \\
\hline Paid any informal fees to deliver her baby & 73.6 & 87.2 & 69.6 & 22.5 & $\mathrm{p}$ & $<0.001$ \\
\hline Clean cloth and Macintosh sheet was used during birth & 52.8 & 30.6 & 83.3 & 75.0 & $\mathrm{p}$ & $<0.001$ \\
\hline Woman was allowed to assume position of her choice during birth & 43.5 & 21.7 & 67.7 & 80.0 & $\mathrm{p}$ & $<0.001$ \\
\hline Female healthcare providers was present to assist her during childbirth & 82.6 & 79.4 & 89.2 & 80.0 & & \\
\hline Woman was forced to go for caesarean or assisted delivery & 16.5 & 5.6 & 41.2 & 2.5 & $\mathrm{p}$ & $<0.001$ \\
\hline Doctor was harsh while assisting her during the childbirth & 37.3 & 48.9 & 17.7 & 35.0 & $\mathrm{p}$ & $<0.001$ \\
\hline Woman was physically restrained & 27.3 & 37.2 & 12.8 & 20.0 & $\mathrm{p}$ & $<0.001$ \\
\hline Woman was separated from her baby unless medically necessary & 18.0 & 17.8 & 13.7 & 30.0 & $\mathrm{p}$ & $<0.10$ \\
\hline
\end{tabular}

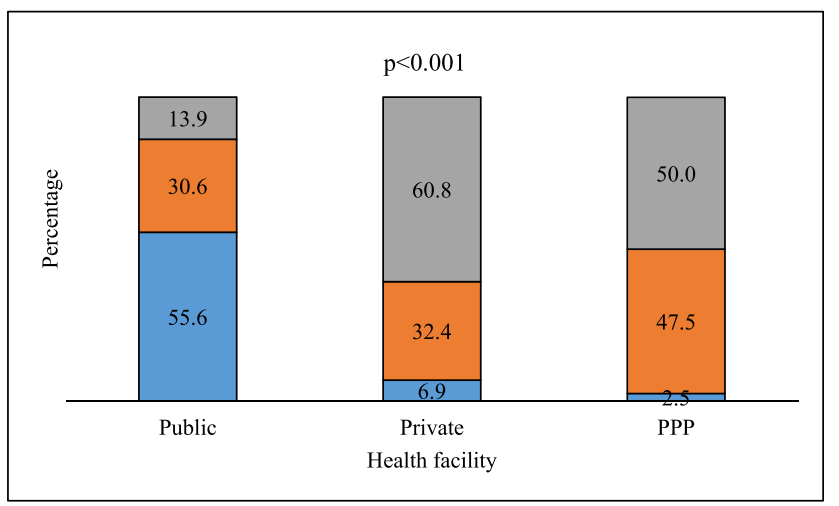

Fig. 2. Level of respectful maternity care during childbirth by health facility.

groups (53\%), from affluent households (46\%), with higher secondary and above level of education (58\%), their spouse studied up to higher secondary and above level (42\%), spouse with salaried job (42\%), married after attaining minimum age at marriage i.e. 18 years $(46 \%)$, married for 5 and less years (38\%), given first childbirth at aged above 20 years (46\%) and with one CEB (35\%) received high level of respectful maternity care more than their counterpart respondents from rural (26\%), SCs/STs social group (26\%), poor families $(24 \%)$, with primary education (20\%), their spouse with primary education $(22 \%)$, spouse without any job (13\%), married before attaining minimum age at marriage i.e. 18 years (25\%), married for 6 and more years (25\%), given first childbirth at aged below 20 years (23\%) and with 2 and more CEB (20\%) (Table 2).

A respondent who delivered in the district hospital in Ganjam said, "The staff nurse injected me without much care because I was calling her repeatedly to assist during labour pain. I complained about such inhuman treatment however no action was taken." (District Hospital, Ganjam; Caesarean delivery; Male child; DOB: October 6, 2015)".

Gitanjali Digal (name changed) a Schedule Caste respondent said, "I was asked to vacate bed before my bleeding could stop to accommodate another woman who was from better-off family and was known to the medical staffs."

It is evident in Table 3 that, respondents having visited Private and PPP health facilities received high level of respectful maternity care more than the respondents who delivered in Public facilities. Nevertheless, respondents from urban area, from affluent households, with higher secondary and above education, married after attaining the minimum age at marriage (i.e. 18 years) and accompanied by spouse at the delivery received high level of respectful care more than their
Table 2

Covariates of respectful maternity care during childbirth of respondents.

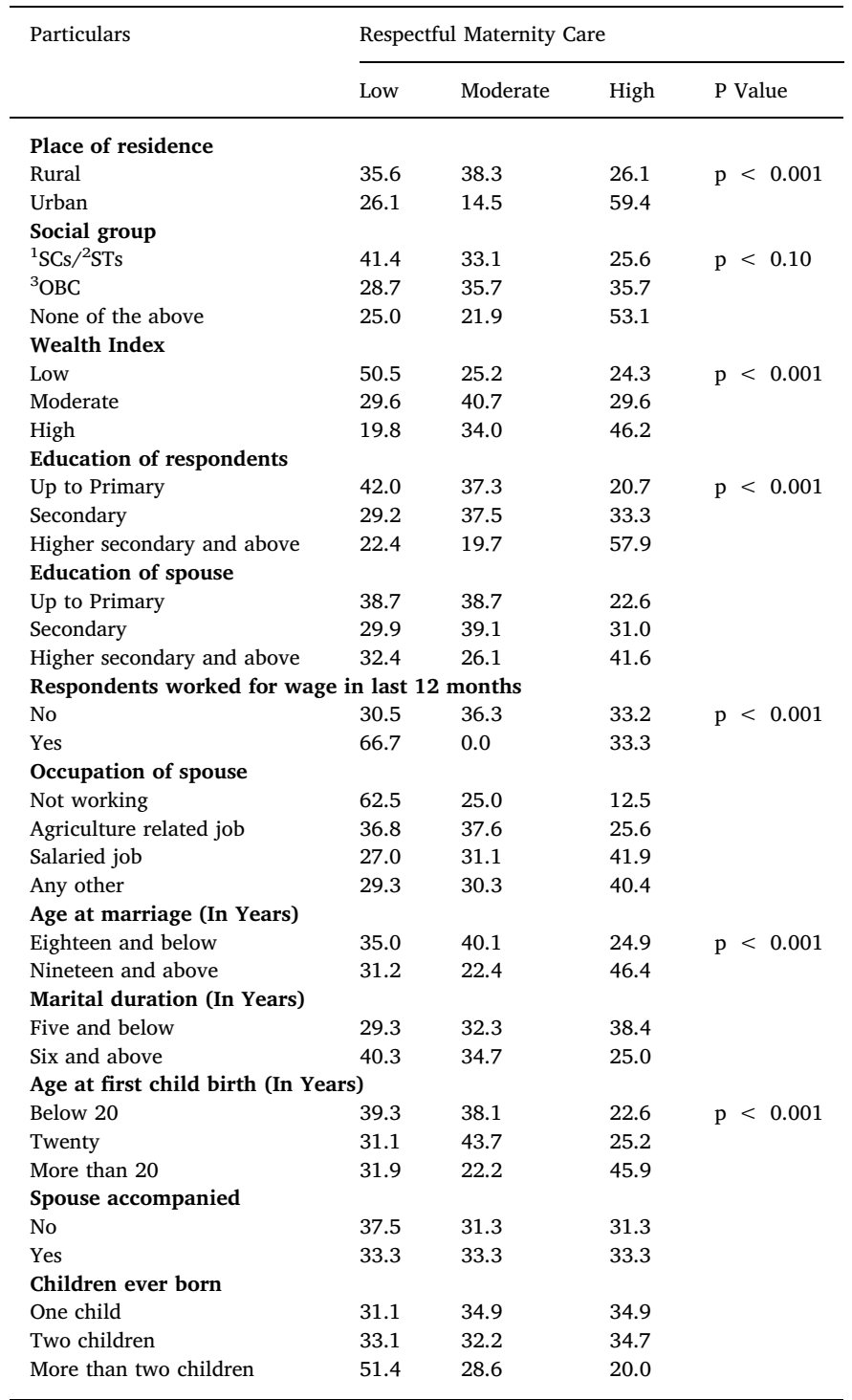

1 Scheduled Caste 2 Scheduled Tribes 3 Other Backward Classes. 
Table 3

Respondents received high level of respectful maternity care by health facility.

\begin{tabular}{|c|c|c|c|c|c|}
\hline \multirow[t]{2}{*}{ Particulars } & \multicolumn{3}{|c|}{ Health facility } & \multicolumn{2}{|c|}{ P Value } \\
\hline & Public & Private & PPP & & \\
\hline \multicolumn{6}{|l|}{ Place of residence } \\
\hline Rural & 7.9 & 47.3 & 50.0 & $\mathrm{p}$ & $<0.001$ \\
\hline Urban & 34.2 & 96.4 & - & & \\
\hline \multicolumn{6}{|l|}{ Social group } \\
\hline${ }^{1} \mathrm{SCs} /{ }^{2} \mathrm{STs}$ & 8.9 & 56.7 & 41.7 & & \\
\hline${ }^{3} \mathrm{OBC}$ & 13.1 & 61.4 & 62.5 & & \\
\hline None of the above & 41.2 & 66.7 & - & & \\
\hline \multicolumn{6}{|l|}{ Wealth Index } \\
\hline Low & 7.9 & 59.3 & 36.8 & $\mathrm{p}$ & $<0.001$ \\
\hline Moderate & 10.2 & 61.1 & 69.2 & & \\
\hline High & 29.6 & 63.3 & 50.0 & & \\
\hline \multicolumn{6}{|l|}{ Education of respondents } \\
\hline Up to Primary & 4.2 & 50.0 & 50.0 & $\mathrm{p}$ & $<0.001$ \\
\hline Secondary & 12.5 & 48.2 & - & & \\
\hline Higher secondary and above & 36.4 & 87.5 & - & & \\
\hline \multicolumn{6}{|l|}{ Education of spouse } \\
\hline Up to Primary & 4.8 & 100.0 & - & & \\
\hline Secondary & 16.7 & 48.6 & 56.7 & & \\
\hline Higher secondary and above & 19.7 & 66.7 & 30.0 & & \\
\hline \multicolumn{6}{|c|}{ Respondents worked for wage in last 12 months } \\
\hline No & 14.9 & 57.5 & 50.0 & $\mathrm{p}$ & $<0.10$ \\
\hline Yes & 5.3 & 100.0 & - & & \\
\hline \multicolumn{6}{|l|}{ Occupation of spouse } \\
\hline Not working & 0.0 & 50.0 & - & & \\
\hline Agriculture related job & 2.6 & 59.1 & 55.9 & & \\
\hline Salaried job & 24.4 & 74.1 & 16.7 & & \\
\hline Any other & 26.0 & 55.1 & & & \\
\hline \multicolumn{6}{|l|}{ Age at marriage (In Years) } \\
\hline Eighteen and below & 11.0 & 45.6 & 35.5 & $\mathrm{p}$ & $<0.001$ \\
\hline Nineteen and above & 18.3 & 80.0 & 100.0 & & \\
\hline \multicolumn{6}{|l|}{ Marital duration (In Years) } \\
\hline Five and below & 14.7 & 67.2 & 56.3 & & \\
\hline Six and above & 12.8 & 50.0 & 25.0 & & \\
\hline \multicolumn{6}{|c|}{ Age at first child birth (In Years) } \\
\hline Below 20 & 12.3 & 41.2 & 50.0 & $\mathrm{p}$ & $<0.001$ \\
\hline Twenty & 10.0 & 43.8 & 33.3 & & \\
\hline More than 20 & 17.8 & 77.4 & 88.9 & & \\
\hline \multicolumn{6}{|l|}{ Spouse accompanied } \\
\hline No & 22.2 & 50.0 & 40.0 & & \\
\hline Yes & 13.5 & 61.0 & 51.4 & & \\
\hline \multicolumn{6}{|l|}{ Children ever born } \\
\hline One child & 7.6 & 60.6 & 57.1 & & \\
\hline Two children & 19.1 & 61.8 & 42.1 & & \\
\hline More than two children & 18.2 & 50.0 & - & & \\
\hline
\end{tabular}

1 Scheduled Caste 2 Scheduled Tribes 3 Other Backward Classes - No Cases.

Table 4

Effect of different health facility to delivering respectful maternity care - propensity score matching result.

\begin{tabular}{llllll}
\hline Facilities & Treated & Controlled & ATT & Standard Error & T \\
\hline Public & 178 & 78 & -5.503 & 0.608 & -9.047 \\
Private & 28 & 48 & -0.746 & 2.537 & -0.294 \\
PPP & 40 & 84 & 7.475 & 1.085 & 6.888 \\
\hline
\end{tabular}

Note: The numbers of treated and controls refer to actual nearest neighbour.

corresponding counterparts group.

Using the nearest neighbourhood matching with replacement method, the result of propensity score matching evidently shows that, using PPP facilities has positive bearing on respectful maternity care (ATT: 7.475; SE: 1.085 ; T: 6.888). The average treatment on the treated (ATT) for the public and private is negative depicting an adverse relationship with respectful maternity care. Yet, accessing public facilities (ATT: -5.503) has noticeable negative effect on respectful maternity care than private facilities (ATT: -0.746) (Table 4).

A poor respondent in one FGD said, "Even if the care is good in private facilities, it's very expensive. It is only for rich people. I can't afford it. They ask to do so many tests without medically necessary, if possible in the emergency ward only to increase the total cost of the healthcare."

\section{Discussion}

The present study is the first of its kind which assessed the maternal healthcare service provision from human rights perspective in Odisha an infamous state for its high maternal morbidity and mortality in India. ${ }^{5,24}$ The other novelty of this study is that, it included respondents from three differently managed i.e. public, private and public-private partnerships health facilities to have a comparative assessment with reference to their experience during childbirth. The findings of the study present a distinct picture wherein respectful and dignified delivery care is not accessible to all the respondents incorporated in the study. Management of the health facility earmarked as the major transpiring factor to availing respectful maternity care during difficult phase like childbirth. In a nutshell, respondents having accessed public facilities which happened to be the largest service provider in the study population ${ }^{25}$ received more abusive and disrespectful care. This was true across the physical attributes and household characteristics of the respondents. Nevertheless, respondents in public facilities from poor households, from SCs/STs social group, from rural area, without education, not worked for wage in the last 12 months, married before attaining the minimum legal age (i.e. 18 years) and have become mother at early age received more disrespectful and abusive care during childbirth.

Paying informal fees to receive care, not providing comfort/painrelief in medically urgency, not using clean cloth and Macintosh sheet during birth, not allowing birth companion to stay with respondent wherever it was possible, denying food or fluid to respondent in labour unless it was medically necessitated and being harsh while assisting respondent during labour pain or childbirth emerged as the most common forms of abusive and disrespectful care that prevailed in the public facilities.

Contrary to this, no concrete evidence found in the descriptive and statistical analysis to belief that, private and PPP facilities do render abusive and disrespectful care alike the public counterparts. Yet, the acquired propensity score is not in favour of the private facilities to providing respectful maternity care. The average treatment on the treated (ATT) for the private facilities although very minimal but suggest an adverse effect on the respectful maternity care. It is observed in the present study that, respondents having accessed private facilities were forced to have caesarean or assisted delivery ( $\mathrm{p}<0.001$ ). The recently concluded large scale surveys and many others found that, incidence of caesarean deliveries is disproportionately high in private facilities as compared to any other managed health facilities. This is true irrespective of woman reporting any complication either during gestation or at the time of delivery. ${ }^{5,26}$ The assessment of qualitative information also supplemented these quantitative inferences.

The PPP health facilities incorporated in the study found to have positive bearing to providing respectful maternity care. In PPP facilities, birth companion was allowed to remain with respondents wherever it was possible ( $\mathrm{p}<0.001)$. Clean cloth and Macintosh sheet was used during birth $(\mathrm{p}<0.001)$ and respondents were allowed to assume position of her choice during birth $(\mathrm{p}<0.001)$ and respondents were hardly forced to go for caesarean or assisted delivery.

A study conducted in Gujarat corroborated the findings of the present study that, after the introduction of PPP as a reformative measure through the Chiranjeevi Yojana in the healthcare, the institutional birth rose from $40.7 \%$ in 2001 to $89.3 \%$ in $2010 .{ }^{21}$ Another study undertaken in Odisha critically examined the performance of Primary health centres (PHC) under government (PHC-GOV), NGO (PHC-NGO) and corporate (PHC-COR) and found that, there is no significant variation in the breadth and depth of services across all the three models of PHC management. The study further argued that, PHC-GOV had better accessibility, infrastructure, behaviour of doctors and availability of 
medicines, whereas laboratory service was better in PHC-NGO and PHC-COR. ${ }^{27} \mathrm{~A}$ study while analysing the challenges of PPP health facilities suggests that, involvement of NGOs in health planning is nearly non-existence but government expect them to participate in the final phase of implementation of any programs. Further, the mismatch between the grassroots needs and the government agenda make the partnership more complex. Very often, an NGO working at the grassroots with the community recognises communicable diseases and reproductive health as a major problem, whereas the government actively supports proposals that are target-oriented, pre-conceived and may not have anything to do with the local realities. The unequal nature of relationships and the red-tape involved in getting programs sanctioned and while releasing budget from the government obstruct the work of PPP run health facilitiesin India. ${ }^{28}$

The qualitative information gathered with the help of FGDs and IDs from respondents and service providers evidently corroborated the findings of quantitative analysis that, respondents across the socioeconomic and demographic covariates did not receive equal care in the health facilities.

\section{Conclusion}

Women's memory of birth experience stays with her lifetime. Any disrespectful and abusive care during childbirth bound to affect her physical and emotional health adversely and would damage her motive to seek future healthcare services. ${ }^{29}$ It may discourage women to access health facility for delivery care - by which, opportunities may be lost to diagnose morbidities early that are associated with pregnancy and childbirth. This may widen the gap further with more illness and deaths in Odisha - which already has an uneven burden of high maternal morbidity and mortality. A timely provision of respectful maternity care especially in the public health facilities may increase the utilisation of essential maternity care among women in Odisha. Such development will help India at large to achieve the recently crafted Sustainable Development Goals 3 (SDG 3), which envisage to the target of less than 70 maternal deaths, per 100,000 live births by 2030 . This requires an annual rate of reduction of at least $7.5 \%$, more than double the annual rate of progress achieved between 2000 and $2015 .^{30}$ Even if the goal is met without protecting the respectful maternity care, it defeats the whole purpose of keeping childbearing in human rights perspectives.

\section{Limitation}

There are few aspects that needs to be kept in mind while considering the findings of this study.

o By using a small sample size, the study explored a new dimension in healthcare service delivery system. The result may be applied across the sub-groups in general but not as the true representative of the population.

o Although, the tool used in this study is scientific and reliable to collect information about the respectful maternity care objectively. The respondents had the sole authority to attribute any specific experience as disrespectful and abusive which could be biased in his/her judgment.

o Since the childbirth related experience was collected retrospectively there may be possibility of loss of memory of respondents about the eventualities during childbirth.

\section{Ethical approval}

The ethical clearance was obtained from Students Research Ethics Committee (SREC) of the International Institute for Population Sciences (www.iipsindia.org) before undertaking the study. Apart from this, prior consent from respondents was obtained to collecting information from them. The prior consent was acquired after presenting the utility of the present study. Anonymity of participant's identity was maintained throughout the study. The information collected from respondents have been kept strictly confidential and used only for research purpose.

\section{Funding statements}

The Parkes foundation was very generous to support financially for the data collection in the study.

\section{Declaration of competing interest}

The authors declare that, there is no conflict of interest.

\section{Acknowledgement}

The authors thank the respondents for their active participation. Thank is also due to the anonymous reviewers and editor of this journal for their suggestions to improve the article.

\section{References}

1. Krishnaraj M. Motherhood in India: glorification without empowerment ? Routledge India. Accessed on 12 August 2017; Available at https://books.google.co.in/books? $\mathrm{id}=$ WMmq85yTuvoC\&pg $=$ PA9\&source $=$ gbs_toc_r\&cad $=2 \# \mathrm{v}=$ onepage\&q\&f $=$ false; 2012.

2. Bahadur A, Dhawan N. Social value of parents and children in joint and nuclear families. J Indian Acad Appl Psychol. 2008;34:74-80.

3. Nair H, Panda R. Quality of maternal healthcare in India: has the national rural health mission made a difference? J Global Health. 2011;1:79.

4. Prata N, Tavrow P, Upadhyay U. Women's empowerment related to pregnancy and childbirth: introduction to special issue. BMC Pregnancy Childbirth. 2017; 17:352.

5. International Institute for Population Sciences (IIPS), ICF. National Family Health Survey (NFHS-4), 2015-16: India. Mumbai: IIPS; 2017.

6. Arora SVP. Maternal mortality-Indian scenario. Med J Armed Forces India. 2005;61:214-215.

7. World Health Organization. Maternal mortality fact sheet. Accessed on 24th May 2017. Available at http://www.who.int/mediacentre/factsheets/fs348/en/; 2014.

8. Sines E, Syed U, Wall S, Worley H. Postnatal Care: A Critical Opportunity to Save Mothers and Newborns. Policy Perspectives on Newborn Health; 2007:1-4.

9. Pathak PK, Singh A, Subramanian SV. Economic inequalities in maternal health care: prenatal care and skilled birth attendance in India, 1992-2006. PloS One. 2010;5(10):e13593.

10. Gopalan SS, Mohanty S, Das A. Challenges and opportunities for policy decisions to address health equity in developing health systems: case study of the policy processes in the Indian state of Orissa. Int J Equity Health. 2011;10(1):55.

11. Kishor S, Gupta K. Gender Equality and Womens Empowerment in India. India: National Family Health Survey(NFHS-3); 2009 2005-06.

12. Singh PK, Kumar C, Rai RK, Singh L. Factors associated with maternal healthcare services utilization in nine high focus states in India: a multilevel analysis based on 14385 communities in 292 districts. Health Pol Plann. 2013;29(5):542-559.

13. Jewkes R, Abrahams N, Mvo Z. Why do nurses abuse patients? Reflections from South African obstetric services. Soc Sci Med. 1998;47(11):1781-1795.

14. Bowser D, Hill K. Exploring Evidence for Disrespect and Abuse in Facility-Based Childbirth. Boston: USAID-TRAction Project, Harvard School of Public Health; 2010.

15. Van Duong D, Binns CW, Lee AH, Hipgrave DB. Measuring client-perceived quality of maternity services in rural Vietnam. Int J Qual Health Care. 2004;16(6):447-452.

16. Campbell OM, Graham WJ, Lancet Maternal Survival Series steering group. Strategies for reducing maternal mortality: getting on with what works. Lancet. 2006;368(9543):1284-1299.

17. Bhattacharyya S, Srivastava A, Avan BI. Delivery should happen soon and my pain will be reduced: understanding women's perception of good delivery care in India. Glob Health Action. 2013;6(1):22635.

18. Adamson PC, Krupp K, Niranjankumar B, Freeman AH, Khan M, Madhivanan P. Are marginalized women being left behind? A population-based study of institutional deliveries in Karnataka, India. BMC Publ Health. 2012;12(1):30.

19. Ram F, Singh A, Ram U. Human rights approach to maternal \& child health: has India fared well? Indian J Med Res. 2013;137(4):721.

20. Sen G, Reddy B, Iyer A. Beyond measurement: the drivers of disrespect and abuse in obstetric care. Reprod Health Matters. 2018;26(53):6-18.

21. De Costa A, Vora KS, Ryan K, Raman PS, Santacatterina M, Mavalankar D. The stateled large scale public private partnership 'ChiranjeeviProgram'to increase access to institutional delivery among poor women in Gujarat, India: how has it done? What can we learn? PloS One. 2014;9(5):e95704.

22. Human Development Index. Orissa Report Government of Orissa; 2004 Accessed on 14th August 2014. Available at human_development_report_2004_orissa_full_report.pdf.

23. Windau-Melmer T. A guide for advocating for respectful maternity care. Accessed on $30^{\text {th }}$ May 2017. Available at https://www.whiteribbonalliance.org/wp-content/ 
uploads/2017/11/RMC-Guide_FINAL.pdf; 2013

24. Prusty RK, Gouda J, Pradhan MR. Inequality in the utilization of maternal healthcare services in Odisha, India. Int J Popul Res. 2015;2015.

25. Raut MK, Sekher TV. Decentralization of health care systems: findings from Odisha and Gujarat, India. J Health Manag. 2013;15(2):235-251.

26. Singh P, Hashmi G, Swain PK. High prevalence of cesarean section births in private sector health facilities-analysis of district level household survey-4 (DLHS-4) of India. BMC Publ Health. 2018;18(1):613.

27. Baig MB, Panda B, Das JK, Chauhan AS. Is public private partnership an effective alternative to government in the provision of primary health care? A case study in
Odisha. J Health Manag. 2014;16(1):41-52.

28. Mukhopadhyay A. Public-private Partnership in the Health Sector in India. 2000; 2000 PUBLIC-PRIVATE PARTNERSHIPS 333. Accessed on 23rd Sept 18. Available at http://unpan1.un.org/intradoc/groups/public/documents/apcity/unpan047037. pdf.

29. Simkin P. Just another day in a woman's life? Women's long-term perceptions of their first birth experience. Part I. Birth. 1991;18(4):203-210.

30. U.N.. United nations sustainable development goals. Accessed on 24th Sept 18 . Available at http://www.undp.org/content/dam/undp/library/corporate/brochure/ SDGs_Booklet_Web_En.pdf; 2015. 